\title{
A Case Study of Internationalisation in Chinese Non-government Institutions
}

\author{
Mei Wang ${ }^{1}$, Lindsey Conner ${ }^{2}$, Bev Rogers ${ }^{2}$ \\ ${ }^{1}$ College of Education, Psychology \& Social Work, Flinders University, Australia; \\ Changchun University of Architecture and Civil Engineering, China, ${ }^{2}$ College of Education, \\ Psychology \& Social Work, Flinders University, Australia.
}

\begin{abstract}
China's non-government Higher Education sector has experienced 40 years of growth but has faced a range of problems in recent years. There is an urgent need to think carefully about future directions and approaches that nongovernment universities might take. Internationalisation is changing the world of education and has become important strategically for Higher Education institutions across the world. This research explores what internationalisation might mean and provides an understanding of internationalisation in the context of Chinese non-government universities. Under the internationalisation framework in Western academic literature, this study investigates the practice from a case study university in China. Data were collected through semi-structured interviews along with document analysis. Participants indicated that internationalisation is learning, integrating initiatives for mutual benefit and can be an accelerator for overall development of universities. Furthermore, the government and society need to work together to create a more equitable government policy that positively encourages China's non-government Higher Education institutions to bolster internationalisation.
\end{abstract}

Keywords: China, non-government institutions, internationalisation. 


\section{Introduction}

China undertook economic reform and issued the first opening-up policy in 1978. At the same time, China started to open the Higher Education (HE) system to the world. Since then, the Chinese HE system has grown to be the largest in the world in terms of student enrolments (Hammond, 2016; van der Wende \& Zhu, 2016). As well, China has become a popular destination for study abroad (Hammond, 2016; Kirby \& van der Wende, 2018).

As a product of the Chinese Opening-up policy and HE structural reform, Chinese Nongovernment HE Institutions (NgHEIs) re-emerged in the early 1980s and have become one of the important components of Chinese HE. By the end of 2018, there were 2663 Regular HEIs in China, with 749 NgHEIs, accounting for $28.13 \%$ of the total universities in China (MOE, 2019).

Private HE has relieved the pressure of increasing demand for HE and hastened the development of mass HE. However, China's non-government HE sector has faced a range of problems in recent years marked by Revised Non-government Education Promotion Law (hereafter: New Law) (MOJ, 2016) in 2016. The New Law introduced a classification management model to divide non-government institutions into two types: Non-profit and For-profit. However, since the New Law has been drafted for four years, there has been neither supporting strategies nor implementation approaches in most provinces in China. In addition, non-government universities face self-development and identity problems as graduate students are not as highly regarded as students from government universities and may have reduced opportunities. These challenges create great uncertainty and there is an urgent need to think carefully about the future directions and approaches that nongovernment universities might take to respond.

Under the impact of economic globalisation and the integration of science and technology, internationalisation is changing the world of education and has become important strategically for HEIs across the world (Altbach, 2002; Gould, 2017; Wihlborg \& Robson, 2018). How could an internationalisation strategy for non-government universities provide an approach to facilitate and link all university activities for ongoing development? Knight (2008) argues "Internationalisation means different things to different people" (p. 1). The purpose of this research is to explore what internationalisation might mean and provide an understanding of internationalisation in the context of Chinese NgHEIs to potentially inform future policy development. This study can also inform Western scholars who wish to understand the internationalisation practice in the Chinese social context and to Western HE institutions who encounter similar challenges. 


\section{Research question}

What is the meaning of internationalisation in Chinese non-government universities?

\section{Research design}

This research employed a qualitative case study methodology. Data was collected from a Chinese non-government university through semi-structured interviews and artifact analysis. Interpretive analysis was used. In guiding this research, the conceptual framework of a Western scholar, Knight (2008), was used to examine China's IHE. Knight (1994) portrays internationalisation as a complex process including: (a) definition, (b) rationale, (3) approach and (4) strategy which can all work together to examine the meaning and process of China's internationalisation of NgHEIs. Neave's model, Davies' model and Rudzki's model are all famous models for internationalisation strategies. However, Knight (1994) and Knight and de Wit (1995) believe internationalisation is a process with many complexities. Knight's model is used here because it provides a holistic frame for examining China's IHE.

Knight's working definition of internationalisation was employed in this study.

Internationalisation at the national, sector and institutional levels as the process of integrating an international, intercultural, or global dimension into the purpose, functions or delivery of postsecondary education (Knight, 2015, p. 2).

Seven top and mid-level leaders, including two university leaders, two department directors and three school deans, came from three campuses of the case university, were interviewed face to face individually in China, in Mandarin. They are all in decision-making positions where they determine the university direction, create university-level policies and the internationalisation strategy, and they lead and motivate faculty and students in their practice.

\section{Findings}

\subsection{The Brief Profile of the Case Study University}

Founded in 1984 in Beijing, NGU is the first new-type of Non-profit university in the publicowned and non-governmental system. The total number of students enrolled was approximately 20,000 with $80 \%$ of them from Beijing. Currently, NGU has more than 40 sister colleges and universities from 20 countries. The international collaboration program in relation to students and faculty is diverse and abundant including high-level projects in China's NgHEIs that have enhanced NGU's social reputation and total development. NGU has successively ranked in the top of non-governmental universities in China since 2011. 


\subsection{The definition of internationalisation at $N G U$}

Participants of NGU view internationalisation from different perspectives. The participants who contributed these ideas are indicated in brackets. In general, these perspectives were categorised into three groups: developing trends, standards, and cultural exchanges. Most importantly, in the context of HEIs in China, it is an approach or goal to learn from others and two-way exchange to create mutual benefits through cross-broader, cross-ethnic and cross-culture activities (NG2, NG4, and NG7). Internationalisation is not Westernisation $\left(\mathrm{NG}^{1}{ }^{1}\right)$ - the process of being internationalised is not learning and accepting others totally, but selectively combines our own problems and characteristics to create knowledge with our own distinctive features. The concept conveyed was one of exporting and spreading knowledge and influencing others for mutual benefits in the future.

\subsection{The rationales of internationalisation at $N G U$}

According to Knight (2008), the traditional rationales for internationalisation include "social and cultural; political; economic; and academic" to examine "Why internationalisation" is important. At NGU, commonly participants considered that both internal and external factors contributed rationales, with internal reasons being stronger.

Internal motivations were for survival and the development of their institution, keeping up with public institutions, as well as meeting the needs of students and faculty.

For example, NG7 introduced the idea that internationalisation was used as a standard to evaluate the quality and reputation of HEIs. This standard forces institutions to foreground internationalisation to ensure their survival.

In addition, participants thought internationalisation was perhaps the quickest way to remedy the gap between their institution with public ones and may assist in catching up with public universities through cooperation with high-quality foreign universities (NG5 and NG7).

\section{External motivation}

Participants recognized that Chinese students wanted to study overseas, but there were also students who wanted to come to China to study (NG5 and NG6). Moreover, China needs international talent to help promote national reform. Thus, graduates with an international vision and background were highly regarded, especially because Chinese people want to share Chinese culture and show the real China to the world (NG3).

\footnotetext{
${ }^{1}$ NGU 1-NGU 7 are references to my seven interview partners for anonymity.
} 


\subsection{Approaches and strategies of internationalisation at $N G U$}

Knight (2008) proposes six groups of approaches: "activity; outcomes; rationales; process; ethos and abroad/cross-border" to frame and examine "How to internationalise". Strategies, programs and policies work together to examine the strategies of internationalisation at the institutional level (Knight, 2008). Strategies are divided into Academic strategies and Organisation strategies. At NGU, approaches were described for each of these strategies.

\section{Organisation strategies, programs and policies at NGU}

The main features of internationalisation practice at NGU were:

1. Positioning internationalisation as an aspirational long-term goal by writing it into the outline and annual plan (NG1, NG2, NG3 and NG5). It helped drive the longterm goal to form a highly-ranked University that is metropolitan, applicationoriented, and international. In addition, all strategies were implemented with the support of human resources, material, energy and financial resources (NG1, NG2, NG4 and NG6).

2. The Internationalisation strategy links closely to the distinctive strength of disciplines and specialties of NGU to provide talent cultivation, teaching, researching and social service. Participants recognised that international cooperation can be enhanced through professional development and talent training (NG3 and NG7). At the university level, they developed international courses through both compulsory and elective courses (NG3 and NG7). At the secondary colleges level, some courses have integrated the issue of internationalisation into the curriculum, such as Community Care, Community Rehabilitation and Aged Care (NG6). NGU has also established the Sino-Danish Senior Citizen Centre in Demark to help deal with global health problems.

3. Balancing the relationship between internationalisation and localisation (NG1, NG4 and NG7) is important. Participants believed NgHEIs were local universities so internationalisation should serve to improve the level of local specialties, local characteristics of culture and industry. In addition, collaboration was not only emphasised in Western countries but to cooperate to access advanced resources throughout the world (NG1, NG2 and NG6). For example, NGU's collaboration with Cuba has created a breakthrough of China in Latin America which has facilitated NGU's social reputation nationally and internationally.

\section{Academic strategies and programs of NGU}

Guided by high-level university strategy and supervised by a motivation management and decentralised system, NGU has created "a platform for international communication and cooperation with distinct levels, diverse types and two-way interaction" (NG4). 
1. In terms of students, NGU has Sino-foreign cooperative education programs at the master's degree level with XX University, a top five university in UK, a Confucius Institute in Italy, a master's program for international students from $B R I$ region, and a double-degree international program and international courses with credits for domestic students. NGU also offers exchange programs with a very clear hierarchy according to the level and discipline of students in different grades (NG4 and NG5). In addition, they care about students who do not have any opportunities or financial resources to go abroad, and undertake "internationalisation at home" as well as extra-curricular activities to benefit these students (NG4). The above collaborations which covered high-level (masters), national strategies (BRI) and programs integrated into local teaching have greatly improved NGU's reputation and total development.

2. In terms of faculty, scientific research and social service, short-term exchange and semester visiting scholar programs for teaching and learning were common (NG2 NG7). NGU has also set up several international scientific cooperation platforms, for research projects and joint publishing opportunities. In addition, many social service projects have cooperated with foreign teachers and sister institutions (NG4).

\section{Discussion}

In 2010, China overtook Japan as the world's second-largest economy. In the same year, the Outline of the National Medium - and Long-Term Programme for Education Reform and Development (2010-2020) (hereafter: 2010 Outline) was issued by the MOE in May 2010. The 2010 Outline stressed the requirement to develop human capital and innovative personnel for national economic growth (MOE, 2010). In addition, the Vision and Actions on Jointly Building the Silk Road Economic Belt and the 21st Century Maritime Silk Road (hereafter: BRI) (NDRC, 2015) was released in 2015, which guided the direction of internationalisation of HEIs in China to promote extensive cultural and academic exchanges through two-way interaction among students particularly in the $B R I$ region.

Under these national and policy contexts, Chinese HEIs have contributed to international talent cultivation and the national BRI strategy. NGU is not an exception. Due to its short history and limited resources compared with public universities, as well as some marginalised within the Chinese HE system, self-development and keeping up with public universities have become the principal rationale as well as political rationale such as serving the state and sharing the culture/social aspects that are driven by patriotism and social community. This is quite different from the current trend of internationalisation in most Western countries, where revenue generation has become the primary driving rationale behind internationalisation of HE (Altbach \& Knight, 2007; Redden, 2016; Wadhwa \& Jha, 2014). 
Facing self-development issues, the stress from the public sector and the uncertain national New Law for the non-government sector, leaders at NgHEIs, as shown in this case study, have a strong commitment and great expectations for internationalisation. As such, internationalisation is highly regarded as an important strategy to facilitate the distinctive strengths and enhance the quality of institutions. The non-profit orientation, the flexible system and the supported funding from the institution itself, has created a positive policy and cultural atmosphere for leaders, faculty and students to engage in internationalisation, as well enabling NGU to consider other ways to attract government support and social recognition.

NGU had a range of high-level communication and cooperation programs for students and facility that were both domestic and international. Most of the programs were reflected through teaching, researching, social service and cultural heritage. NGU's practice was consistent with Knight's definition of internationalisation as "the process of integrating an international, intercultural, or global dimension into the purpose, functions or delivery of postsecondary education". According to (Wu, 2019), Western experience is relatively limited in practicality. Committed to building a multilateral international cooperation platform (Xiong, 2019) and grounded in local contexts, NGU integrates its development goals and current situation with Western experience, yet is committed to create its own characteristics through transformation and innovation. Thus, it views its' internationalisation strategies as contributing to national and global development through learning and sharing.

However, there are barriers to access internationalisation. The language ability of students and the lack of cutting-edge knowledge and stressful work pace for faculty were the core internal barriers to advancement. Furthermore, inequitable government policies between public and non-government sectors and lower social reputation, for NgHEIs, have a negative impact that attributes lower status and fewer resources of students, faculties and institutions to non-government universities. The external barriers have led to the internal problems which have limited the development of internationalisation in NgHEIs.

\section{Conclusion}

This case study has provided insights about a Chinese non-government university and demonstrates that Knights' view of internationalisation is useful in considering nongovernement universities in China. In the context of China's NgHEIs, internationalisation is positioned as an accelerator for self-development, an important option for public and nongovernment universities to develop in parallel, a process of two-way interaction, integration, mutual benefits and cultural transmission. An implication of the findings from this case study could be that $\mathrm{NgHEIs}$, the government and the society work together to create an equitable government policy to reduce the internal issues of HEIs, such as subsidising China's NgHEIs to become more internationalised. 


\section{References}

Altbach, P. (2002). Perspectives on internationalizing higher education. International higher education(27), 29-31.

Altbach, P., \& Knight, J. (2007). The Internationalization of Higher Education: Motivations and Realities. Journal of Studies in International Education, 11(3-4), 290-305. doi:10.1177/1028315307303542

Gould, R. R. (2017, March, 6). Why internationalisation matters in universities. The Conversation.

Hammond, C. D. (2016). Internationalization, nationalism, and global competitiveness: a comparison of approaches to higher education in China and Japan. Asia Pacific education review, 17(4), 555-566.

Kirby, W., \& van der Wende, M. (2018). The New Silk Road: Implications for Higher Education in China and the West? Cambridge Journal of Regions, Economy and Society, 12(1), 127-144. doi:10.1093/cjres/rsy034

Knight, J. (1994). Internationalization: Elements and Checkpoints. (Vol. 7): ERIC.

Knight, J. (2008). Higher education in turmoil: The changing world of internationalisation. . the Netherlands: Brill Sense.

Knight, J. (2015). Updating the Definition of Internationalization. International higher education(2), 33.

Knight, J., \& de Wit, H. (1995). Strategies for internationalisation of higher education: Historical and conceptual perspectives. Strategies for internationalisation of higher education: A comparative study of Australia, Canada, Europe and the United States of America, 5, 32.

MOE. (2010). National Outline for Medium and Long-Term Education Reform and Development (2010-2020). Beijing: Ministry of Education of PRC

MOE. (2019). The Development of Education in 2018. Beijing: Ministry of Education of the People's Republic of China

MOJ. (2016). Decision on Amending China's Non-Government Education Promotion Law. Bejing: Ministry of Justice of the People's Republic of China

NDRC. (2015). The "Vision on Jointly Building Silk Road Economic Belt and 21st-Century Maritime Silk Road”. Bejing: National Development and Reform Commission of the People's Republic of China

Redden, E. (2016, February 24). A Big World Out There Researchers survey the landscape of internationalization in higher education. Insider Higher Ed.

van der Wende, M., \& Zhu, J. (2016). China: a Follower or Leader in Global Higher Education? Research \& Occasional Paper Series: CSHE. 1.16. .

Wadhwa, R., \& Jha, S. (2014). Internationalization of higher education: Implications for policy making. Higher Education for the Future, 1(1), 99-119.

Wihlborg, M., \& Robson, S. (2018). Internationalisation of higher education: drivers, rationales, priorities, values and impacts. European Journal of Higher Education, 8(1), 8-18. doi:10.1080/21568235.2017.1376696 
Wu, D. (2019). In Pursuit of the "China Experience" in Higher Education. China Higher Education Research, 12, 10-14. doi:10.16298/j.cnki.1004-3667.2019.12.02

Xiong, J. (2019). Internationalization of Higher Education: From Learning to Developing in Parallel and Leading. China Higher Education, 19. 